\title{
NLRP1 polymorphisms in patients with asbestos-associated mesothelioma
}

\author{
Martina Girardelli ${ }^{1}$, Iva Maestri ${ }^{3}$, Rosa R Rinaldi ${ }^{4}$, Mauro Tognon ${ }^{5}$, Renzo Boldorini ${ }^{6}$, Massimo Bovenzi ${ }^{7}$, \\ Sergio Crovella ${ }^{2}$ and Manola Comar ${ }^{2^{*}}$
}

\begin{abstract}
Background: An increasing incidence of malignant mesothelioma (MM) cases in patients with low levels of asbestos exposure suggests the interference of alternative cofactors. SV40 infection was detected, as co-morbidity factor, only in 22\% of asbestos-MM patients from a North-Eastern Italy area. An additional mechanism of injury related to asbestos exposure in $\mathrm{MM}$ development has been recently associated to inflammatory responses, principally driven by interleukin (IL)-1 beta (B) activated within the inflammasome complex.

NLRP3 inflammosome has been described as the intracellular sensor for asbestos able to induce inflammasome activation and IL-1ß secretion while NLRP1 is expressed in lung epithelial cells and alveolar macrophages and contributes to the immune response and to survival/apoptosis balance. This study proposes to evaluate the impact of known NLRP3 and NLRP1 polymorphisms in the individual susceptibility to asbestos-induced mesothelioma in subjects from a hyperendemic area for MM.
\end{abstract}

Methods: 134 Italian patients with diagnosis of mesothelioma due (MMAE, n=69) or not (MMAF, n=65) to asbestos, 256 healthy Italian blood donors and 101 Italian healthy subjects exposed to asbestos (HCAE) were genotyped for NLRP1 (rs2670660 and rs12150220) and NLRP3 (rs35829419 and rs10754558) polymorphisms.

Results: While NLRP3 SNPs were not associated to mesothelioma, the NLRP1 rs 12150220 allele T was significantly more frequent in MMAE (0.55) than in HCAE (0.41) ( $p=0.011$; $O R=1.79)$ suggesting a predisponent effect of this allele on the development of mesothelioma. This effect was amplified when the NLRP1 rs2670660 allele was combined with the NLRP1 rs12150220 allele ( $\mathrm{p}=0.004$; $\mathrm{OR}=0.52$ ).

Conclusion: Although NLRP3 SNPs was not involved in mesothelioma predisposition, these data proposed NLRP1 as a novel factor possibly involved in the development of mesothelioma.

Keywords: Mesothelioma, Asbestos, Inflammasome, NLRP1, NLRP3

\section{Background}

The multistage evolution of pleural malignant mesothelioma (MM) is characterized by the occurrence of pathogenetic events involving tumorigenic agents and, among these, the exposure to asbestos fibers results as the main risk factor [1]. Recently, the observation of an increasing incidence of mesothelioma cases in patients with low levels of asbestos exposure suggests a more complex process probably due to the interference of alternative cofactors. (i.e. radiation, other mineral fibers, genetic

\footnotetext{
* Correspondence: comar@burlo.trieste.it

2Institute for Maternal and Child Health-IRCCS "Burlo Garofolo", University of Trieste, Trieste, Italy

Full list of author information is available at the end of the article
}

and viral ones) involved in a complex pathogenic process whereby genomic damage mechanisms work over a long latency period [2-6].

Recent studies emphasize the role of the Simian Virus 40 (SV40) and asbestos as co-carcinogens in causing mesothelioma, lowering the asbestos threshold limit and the latency period of carcinogenesis [7-14]. Nevertheless, the broad variability ( $0 \%$ to $100 \%)$ in the detection of SV40 strain in the different cohort of MM affected patients showed a controversial role of this virus as causative agent.

In Italy, the vast asbestos consumption is generally related to occupational origin and restricted to some geographic area characterized by a higher incident rate

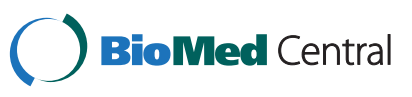


of MM. The contributory role of SV40 infection in MM patients characterized by an "ascertained" asbestosis from an north eastern Italy area hyperendemic for MM, with a standardized incidence rates 4 time higher than the national rate (standard population: Italy census, 2001), showed that SV40 were detected in $22.2 \%$ of the patients, but the data was not found statistically significant [15].

An additional mechanism of injury related to asbestos exposure in MM development has been recently associated to inflammatory responses, principally driven by interleukin (IL)-1 beta (ß) activated within the inflammasome complex [16].

An important role for IL-1ß has been proposed in the pathogenesis of asbestos-induced mesothelioma because it regulates human mesothelial cell proliferation [17], and IL-1ß-driven inflammation is well known to promote the development and invasiveness of several tumor types in vivo [18].

The study by Dorset et al. [19] supports the implication of the Nod-Like Receptor Pyrin domain containing 3 (NLRP3) inflammasome complex in the pulmonary inflammatory diseases linked to asbestos and air pollutants. In addition, polymorphisms in NLRP3 gene have been recently associated with chronic inflammatory diseases, autoimmune disorders and infections [5,6,10,20,21]. Moreover other two SNPs in NLRP1, a gene that codifying for another inflammasome receptor, have been recently reported to contribute to the immune response in lung epithelial cells and alveolar macrophages [14].

Taking in account the previously reported association between variants in NLRP3 gene and an impaired IL-1 production as well as the role of IL-1 driven inflammation in asbestos lung fibrosis and mesothelioma, the aim of this study was to evaluate the impact of the NLRP3 and NLRP1 polymorphisms in the individual susceptibility to asbestos-induced mesothelioma in a cohort of MM patients from a North-Eastern Italy area hyperendemic for malignant pleural mesothelioma. For comparison a series of healthy subjects from the same area at higher risk for environmental and domestic exposure to asbestos and a group of healthy subjects not exposed to asbestos were included as reference control groups.

\section{Results}

We analyzed NLRP3 rs35829419, rs10754558 SNPs and NLRP1 rs2670660, rs12150220 SNPs in 134 Italian patients with mesothelioma, in 256 healthy controls and in 101 individuals exposed to asbestos with no mesothelioma at the age of the enrollment. SNPs frequencies were in Hardy-Weinberg equilibrium in all the groups. The rs2670660 and rs12150220 NLRP1 SNPs as well as rs35829419 and rs10754558 NLRP3 were not in linkage disequilibrium in all the tested groups $\left(\mathrm{r}^{2}<0.9\right)$.
The four SNPs were not significantly different distributed in mesothelioma patients when compared to healthy controls as reported in Table 1.

When we considered asbestos exposure, the two NLRP3 SNPs were not associated to the development of the cancer. The NLRP1 rs2670660 G allele was more frequent in MMAE than in HCAE (0.55 versus 0.43 ), although not significant different after Bonferroni correction $(\mathrm{p}=0.027)$. The NLRP1 rs12150220 $\mathrm{T}$ allele was significantly more frequent in MMAE patients (0.55) than in HCAE (0.41) $(\mathrm{p}=0.011 ; \mathrm{OR}=1.79 ; 95 \% \mathrm{CI}=1.13-2.85)$ (Table 2).

The NLRP1 SNPs combined to form 4 haplotypes which showed a significantly different distribution between MMAE and HCAE ( $\mathrm{p}=0.006)$ (Table 2). In particular the haplotype A-A SNPs was significantly less frequent in MMAE patients than in HCAE (0.40 versus 0.56; $\mathrm{p}=0.004 ; \mathrm{OR}=0.52 ; 95 \% \mathrm{CI}=0.33-0.83)$.

Comparing the two groups of mesothelioma patients (exposed and not exposed to asbestos), no significant difference was observed for all the 4 SNPs as reported in Table 3.

\section{Discussion}

Exposure to asbestos is considered the major risk factor for the onset of MM although its contribution to the pathogenesis is multifaceted and different cofactors exist $[1,22]$. Asbestos induces DNA alterations mostly by inducing mesothelial cells and reactive macrophages to secrete mutagenic oxygen and nitrogen species. In addition, asbestos carcinogenesis is linked to the chronic inflammatory process caused by the deposition of a sufficient number of asbestos fibres and the consequent release of pro-inflammatory molecules [23]. Genetic predisposition, radiation exposureand viral infection are co-factors that can cause MM alone or in association with asbestos and recently also with erionite, an environmental contaminant originating from the volcanic Rocks in Turkey [24].

In a previous study we have reported the presence of SV40 in 22\% of MM patients from a North-Eastern Italy area massively exposed to asbestos in the past, suggesting that an association between SV40 infection and asbestos exposure, as co-morbidity factor, seem to exist [15]. Nevertheless, SV40 infection was reviled only for a small group of patients exposed to asbestos reinforcing the concept that alternative individual host factors could be involved in MM development.

In this study we considered the hypothesis of an association between known NLRP3 single nucleotide variations and asbestos-induced mesothelioma.

NLRP3-inflammasome is known to play an important role in cancer cell transformation [25] and in the immune response against tumors [22,26] and has been described as the intracellular sensor of asbestos [19]. 
Table 1 NLRP3 and NLRP1 allele, genotype and haplotypes frequencies in mesothelioma patients (MM) and healthy controls (HC)

\begin{tabular}{|c|c|c|c|c|c|}
\hline & & $M M(n=134)$ & $\mathrm{HC}(\mathrm{N}=256)$ & $\mathbf{P}$ & OR $(95 \% \mathrm{Cl})$ \\
\hline \multirow[t]{6}{*}{ NLRP3 rs35829419 } & Allele/ Genotype & & & & \\
\hline & A & $10(0.04)$ & $30(0.06)$ & & \\
\hline & C & $258(0.96)$ & $482(0.94)$ & 0.234 & $1.610 .75-3.74$ \\
\hline & A/A & 0 & 0 & & \\
\hline & $\mathrm{C} / \mathrm{A}$ & $10(0.07)$ & $30(0.12)$ & & \\
\hline & $\mathrm{C} / \mathrm{C}$ & $124(0.93)$ & $226(0.88)$ & 0.221 & \\
\hline \multirow[t]{6}{*}{ NLRP3 rs10754558 } & Allele/ Genotype & & & & \\
\hline & G & $113(0.42)$ & $232(0.45)$ & & \\
\hline & C & $155(0.58)$ & $280(0.55)$ & 0.405 & $1.140 .83-1.55$ \\
\hline & $\mathrm{G} / \mathrm{G}$ & $23(0.17)$ & $55(0.21)$ & & \\
\hline & $C / G$ & $67(0.50)$ & $122(0.48)$ & & \\
\hline & $\mathrm{C} / \mathrm{C}$ & $44(0.33)$ & $79(0.31)$ & 0.610 & \\
\hline \multirow[t]{4}{*}{ rs35829419-rs10754558 } & Haplotypes & & & & \\
\hline & $C-C$ & $153(0.57)$ & $282(0.55)$ & 0.459 & \\
\hline & C-G & $107(0.40)$ & $205(0.40)$ & & \\
\hline & $A-G$ & $8(0.03)$ & $25(0.05)$ & & \\
\hline \multirow[t]{6}{*}{ NLRP1 rs2670660 } & Allele/ Genotype & & & & \\
\hline & A & $131(0.49)$ & $235(0.46)$ & & \\
\hline & G & $137(0.51)$ & $277(0.54)$ & 0.450 & $0.890 .65-1.2$ \\
\hline & $\mathrm{A} / \mathrm{A}$ & $33(0.25)$ & $52(0.20)$ & & \\
\hline & $A / G$ & $66(0.49)$ & $131(0.51)$ & & \\
\hline & $\mathrm{G} / \mathrm{G}$ & $35(0.26)$ & $73(0.29)$ & 0.604 & \\
\hline \multirow[t]{6}{*}{ NLRP1 rs12150220 } & Allele/ Genotype & & & & \\
\hline & A & $133(0.50)$ & $249(0.49)$ & & \\
\hline & $\mathrm{T}$ & $135(0.50)$ & $263(0.51)$ & 0.821 & $0.950 .71-1.31$ \\
\hline & $\mathrm{AA}$ & $31(0.23)$ & $60(0.23)$ & & \\
\hline & AT & $72(0.54)$ & $129(0.50)$ & & \\
\hline & $\pi$ & $31(0.23)$ & $67(0.26)$ & 0.772 & \\
\hline \multirow[t]{5}{*}{ rs2670660-rs12150220 } & Haplotypes & & & & \\
\hline & G-T & $121(0.45)$ & $236(0.46)$ & 0.588 & \\
\hline & A-A & $118(0.44)$ & $205(0.40)$ & & \\
\hline & G-A & $16(0.06)$ & $41(0.08)$ & & \\
\hline & $A-T$ & $13(0.05)$ & $30(0.06)$ & & \\
\hline
\end{tabular}

Thus, we hypothesized that SNPs influencing the ability to activate the inflammasome and IL-1ß secretion, could affect the response to asbestos, the entity of asbestosinduced inflammation and, finally, the predisposition to develop mesothelioma.

Data from our study did not support this hypothesis because the two SNPs analyzed in NLRP3 gene were not found associated with mesothelioma (Table 1) or with asbestos-induced mesothelioma (Table 3). Although the two analyzed NLRP3 SNPs were already successfully used to associate this gene to various diseases such as autoimmune (type 1 diabetes, celiac disease, SLE) [6] or infectious diseases (HIV-1) [10], it is possible that they could not be totally representative of the entire gene and deeper investigation will be needed to definitively exclude the association between NLRP3 and asbestosinduced mesothelioma.

Nevertheless, our findings disclosed a novel hypothesis about NLR involvement in the development of mesothelioma due to asbestos. Notably, our data showed that the rs2670660 and rs12150220 polymorphisms in NLRP1 gene were not associated to the mesothelioma. (Table 2) 
Table 2 NLRP3 and NLRP1 allele, genotype and haplotypes frequencies in mesothelioma patients and controls exposed to asbestos (MMAE vs HCAE)

\begin{tabular}{|c|c|c|c|c|c|}
\hline & & MMAE (N=69) & HCAE $(n=101)$ & $p$ & OR $(95 \% \mathrm{Cl})$ \\
\hline \multirow[t]{6}{*}{ NLRP3 rs35829419 } & Allele/ Genotype & & & & \\
\hline & A & $7(0.05)$ & $10(0.05)$ & & \\
\hline & C & $131(0.95)$ & $192(0.95)$ & 1 & $0.970 .32-3.10$ \\
\hline & A/A & 0 & 0 & & \\
\hline & C/A & $7(0.10)$ & $10(0.09)$ & & \\
\hline & $\mathrm{C} / \mathrm{C}$ & $62(0.90)$ & $91(0.91)$ & 1 & \\
\hline \multirow[t]{6}{*}{ NLRP3 rs10754558 } & Allele/ Genotype & & & & \\
\hline & G & $58(0.42)$ & $82(0.41)$ & & \\
\hline & C & $80(0.58)$ & $120(0.59)$ & 0.823 & $0.940 .59-1.50$ \\
\hline & $\mathrm{G} / \mathrm{G}$ & $11(0.16)$ & $13(0.13)$ & & \\
\hline & $C / G$ & $36(0.53)$ & $56(0.55)$ & & \\
\hline & $C / C$ & $22(0.31)$ & $32(0.32)$ & 0.842 & \\
\hline \multirow[t]{4}{*}{ rs35829419-rs10754558 } & Haplotypes & & & & \\
\hline & $C-C$ & $80(0.58)$ & $119(0.59)$ & 0.908 & \\
\hline & C-G & $51(0.37)$ & $75(0.37)$ & & \\
\hline & $A-G$ & $7(0.05)$ & $8(0.04)$ & & \\
\hline \multirow[t]{6}{*}{ NLRP1 rs2670660 } & Allele genotype & & & & \\
\hline & A & $62(0.45)$ & $116(0.57)$ & & \\
\hline & G & $76(0.55)$ & $86(0.43)$ & 0.027 & $1.651 .04-2.62$ \\
\hline & A/A & $12(0.18)$ & $30(0.30)$ & & \\
\hline & $A / G$ & $38(0.54)$ & $56(0.55)$ & & \\
\hline & $\mathrm{G} / \mathrm{G}$ & $19(0.28)$ & $15(0.15)$ & 0.059 & \\
\hline \multirow[t]{8}{*}{ NLRP1 rs12150220 } & Allele/ genotype & & & & \\
\hline & A & $62(0.45)$ & $120(0.59)$ & & \\
\hline & $\mathrm{T}$ & $76(0.55)$ & $82(0.41)$ & 0.011 & $1.791 .13-2.85$ \\
\hline & A/A & $11(0.16)$ & $32(0.32)$ & & \\
\hline & $\mathrm{A} / \mathrm{T}$ & $41(0.59)$ & $56(0.55)$ & & \\
\hline & $\mathrm{T} / \mathrm{T}$ & $17(0.25)$ & $13(0.13)$ & 0.027 & \\
\hline & $\mathrm{T} / \mathrm{T}(\mathrm{A} / \mathrm{T}+\mathrm{A} / \mathrm{A})$ & & & 0.065 & $2.200 .92-5.37$ \\
\hline & $(T / T+A / T) A / A$ & & & 0.030 & $2.431 .08-5.84$ \\
\hline \multirow[t]{5}{*}{ rs2670660-rs12150220 } & Haplotypes & & & & \\
\hline & $A-A^{*}$ & $51(0.40)$ & $114(0.56)$ & $0.006 * 0.004$ & $* 0.52 *(0.33-0.83)$ \\
\hline & G-T & $63(0.50)$ & $80(0.40)$ & & \\
\hline & G-A & $6(0.05)$ & $6(0.03)$ & & \\
\hline & $A-T$ & $6(0.05)$ & $2(0.01)$ & & \\
\hline
\end{tabular}

This unexpected finding may suggest a predisposing effect of NLRP1 to cancer development: this could be explained considering the distribution of NLRP1 throughout the body and the unique role of NLRP1 in apoptosis. According to Kummer [14], NLRP1, and not NLRP3, is expressed in lung in both epithelial cells and alveolar macrophages where NLRP1 inflammasome possibly act as the major danger-sensing platform. The deregulation of NLRP1 inflammasome could contribute to the formation of the pro-tumor micro-environment both influencing the transformation of the lung tissue cells and/or inducing high levels of IL-1ß that contribute to growth and metastatic spread in experimental and human cancers [27-29]. The anti-apoptotic proteins Bcl-2 and Bcl-XL inhibit NLRP1 in a concentration-dependent manner [16]. It could be hypothesized that the rs2670660 G allele and rs12150220 $\mathrm{T}$ allele affect the level of NLRP1 
Table 3 NLRP3 and NLRP1 allele, genotype and haplotypes frequencies in mesothelioma patients exposed and not exposed to asbestos (MMAE vs MMAF)

\begin{tabular}{|c|c|c|c|c|c|}
\hline & & MMAE (N=69) & MMAF $(n=65)$ & $\mathbf{p}$ & OR $(95 \% \mathrm{Cl})$ \\
\hline \multirow[t]{6}{*}{ NLRP3 rs35829419 } & Allele/ Genotype & & & & \\
\hline & A & $7(0.05)$ & $3(0.02)$ & & \\
\hline & C & $131(0.95)$ & $127(0.98)$ & 0.337 & $0.440 .07-1.99$ \\
\hline & $\mathrm{A} / \mathrm{A}$ & 0 & 0 & & \\
\hline & $C / A$ & $7(0.10)$ & $3(0.05)$ & & \\
\hline & $\mathrm{C} / \mathrm{C}$ & $62(0.90)$ & $62(0.95)$ & 0.327 & \\
\hline \multirow[t]{6}{*}{ NLRP3 rs10754558 } & Allele/ Genotype & & & & \\
\hline & G & $58(0.42)$ & $56(0.43)$ & & \\
\hline & C & $80(0.58)$ & $74(0.57)$ & 0.902 & $1.040 .62-1.74$ \\
\hline & $\mathrm{G} / \mathrm{G}$ & $11(0.16)$ & $12(0.19)$ & & \\
\hline & $C / G$ & $36(0.53)$ & $32(0.47)$ & & \\
\hline & $C / C$ & $22(0.31)$ & $21(0.34)$ & 0.946 & \\
\hline \multirow[t]{4}{*}{ rs35829419-rs10754558 } & Haplotypes & & & & \\
\hline & $C-C$ & $80(0.58)$ & $73(0.56)$ & 0.453 & \\
\hline & C-G & $51(0.37)$ & $53(0.41)$ & & \\
\hline & $A-G$ & $7(0.05)$ & $3(0.01)$ & & \\
\hline \multirow[t]{6}{*}{ NLRP1 rs2670660 } & Allele/ genotype & & & & \\
\hline & A & $62(0.45)$ & $70(0.54)$ & & \\
\hline & G & $76(0.55)$ & $60(0.46)$ & 0.179 & $1.430 .86-2.40$ \\
\hline & $\mathrm{A} / \mathrm{A}$ & $12(0.18)$ & $21(0.32)$ & & \\
\hline & $A / G$ & $38(0.54)$ & $28(0.44)$ & & \\
\hline & $\mathrm{G} / \mathrm{G}$ & $19(0.28)$ & $16(0.24)$ & 0.138 & \\
\hline \multirow[t]{6}{*}{ NLRP1 rs12150220 } & Allele/ genotype & & & & \\
\hline & A & $62(0.45)$ & $71(0.55)$ & & \\
\hline & $\mathrm{T}$ & $76(0.55)$ & $59(0.45)$ & 0.142 & $1.470 .89-2.46$ \\
\hline & $\mathrm{A} / \mathrm{A}$ & $11(0.16)$ & $20(0.31)$ & & \\
\hline & $A / T$ & $41(0.59)$ & $31(0.48)$ & & \\
\hline & $\mathrm{T} / \mathrm{T}$ & $17(0.25)$ & $14(0.22)$ & 0.146 & \\
\hline \multirow[t]{5}{*}{ rs2670660-rs12150220 } & Haplotypes & & & & \\
\hline & A.A & $51(0.40)$ & $53(0.41)$ & 0.919 & \\
\hline & G-T & $63(0.50)$ & $62(0.48)$ & & \\
\hline & G-A & $6(0.05)$ & $9(0.07)$ & & \\
\hline & $A-T$ & $6(0.05)$ & $6(0.05)$ & & \\
\hline
\end{tabular}

expression, its function and the balance between cell surviving and apoptosis after injury influencing the mechanism of cell transformation.

Although the frequency of rs2670660 and rs12150220 polymorphism in the general population is relatively high, it does not exist any functional information about this variant. We are aware that our results are preliminary and deeper investigation will be needed to prove these pathogenic hypothesis. However we believe that this strong association between the rs12150220 polymorphism in NLRP1 and asbestos-mesothelioma development emphasizes once more the role of inflammation and inflammasome in tumorigenesis events.

\section{Material and methods}

Samples

One hundred and thirty four blood samples from selected incident cases of Caucasian patients from north eastern Italy areas (Trieste, Ferrara) with malignant pleural mesothelioma were collected in the period 2009-2011 (112 males/22 females; average age 66 (SD 13) years). Of these, 69 showed an ascertained 
occupational asbestos exposure (MMAE) while 65 had no documented history of asbestos exposure (MMAF). In addition, blood samples were collected from 101 healthy subjects ( 84 males/17 females; average age $44 \pm$ 12 yrs) from the same area with previous risk of environmental asbestos exposure (HCAE) and from 256 healthy blood donors (HC; 118 males/138 females; average age $42 \pm 7$ ) not related to the geographic area of patients' group, were analyzed as controls.

Histological examination and classification of tumor were performed according to the World Health Organization criteria [30]. All tumor samples contained a vast majority of malignant cells and minimal stromal, inflammatory or otherwise non-malignant cells or necrotic debris. In addition, histological data on the presence of asbestos fibres (expressed as number /g of dry lung tissue) were also available (range: from 2 to 164.000 asbestos bodies).

The information about asbestos exposure, were obtained using the records of the certified Local Mesothelioma Registry, affiliated to the Italian National Mesothelioma Registry (ReNaM).

The study was approved by the Ethical Committee of the University Hospital "Ospedali Riuniti di Trieste" (Trieste, Italy).

\section{DNA extraction}

Genomic DNA was extracted from peripheral whole blood using the EZ1 DNA purification kit (Qiagen. Milan) following manufacturer's protocols.

\section{SNPs selection and genotyping}

We analyzed 2 SNPs (rs35829419 and rs10754558) in NLRP3 and 2 SNP (rs2670660 and rs12150220) in the NLRP1 genes. SNPs genotyping was performed using commercially available TaqMan assays (Applied Biosystems. Foster City. CA). TaqMan reactions were set up based on the manufacturer's protocol and the samples were run on the ABI7900HT Real-Time PCR platform (Applied Biosystems). Allelic discrimination was performed as suggested by the manufacturer and analyzed using the SDS software (v. 2.3) (Applied Biosystems).

\section{Statistical analysis}

Allelic and genotypic SNP frequencies were calculated using the Genotype Transposer software [31] and then analyzed by Fisher exact test. The Haploview software [32] was used to investigate the association and linkage disequilibrium pattern and for deriving the haplotypes. The open-source $\mathrm{R}$ package (http://www.r-project.org) was used for Fisher exact test and odds ratio (OR) estimation. A formal Bonferroni adjustment for the number of the tests performed would require a significance threshold of $\mathrm{p}=0.013 \quad\left(\mathrm{p}_{0} / \mathrm{N}, \quad \mathrm{p}_{0}=0.05, \quad \mathrm{~N}=4 \quad \mathrm{SNP}\right)$.
Dominant/recessive model has been analyzed according to Lewis [33]. Unadjusted p-values are reported in the text and tables.

\section{Abbreviations}

MM: Malignant mesothelioma; SNP: Single nucleotide polymorphism; MMAE: Mesothelioma due to asbestos exposure; MMAF: Mesothelioma asbestos free; HC: Healthy controls; HCAE: Healthy controls exposed to asbestos; NLRP: Nod like receptor protein.

\section{Competing interests}

The authors declare that they have no competing interests.

\section{Authors' contribution}

$M G, S C$ and MC participated in conception and study design; MG, IM, RR, RB participated in collection, genetic and data analysis; MG, SC participated in statistical analysis and interpretation of the data; MG, MT and MC are involved in the preparation of the paper. All authors reviewed and approved the final paper.

\section{Acknowledgments}

This study was supported, in part, by grants R.C. 11/11 from IRCCS 'Burlo Garofolo" and from Friuli Venezia Giulia Region (969/APREV dd 27.09.2010). S. C. is recipient of a grant from the TALENTS Programme (7th R\&D Framework Programme, Specific Programme: PEOPLE - Marie Curie Actions - COFUND).

\section{Author details}

${ }^{1}$ Institute for Maternal and Child Health-IRCCS "Burlo Garofolo", Trieste, Italy. ${ }^{2}$ Institute for Maternal and Child Health-IRCCS "Burlo Garofolo", University of Trieste, Trieste, Italy. ${ }^{3}$ Department of Experimental and Diagnostic Medicine, Pathology Unit of Pathologic Anatomy, Histology and Cytology University of Ferrara, Ferrara, Italy. ${ }^{4}$ Deartment of Laboratory Medicine, Operative Unit of Anatomy-Pathology, Sant'Anna University Hospital of Ferrara, Ferrara, Italy. ${ }^{5}$ Section of Cell Biology and Molecular Genetics, School of Medicine and Surgery, University of Ferrara, Ferrara, Italy. ${ }^{6}$ Department of Medical Sciences, Faculty of Medicine, University of the Piemonte Orientale, Novara, Italy. ${ }^{7}$ Clinical Unit of Occupational Medicine, University of Trieste, Trieste, Italy.

Received: 4 September 2012 Accepted: 1 October 2012 Published: 2 October 2012

\section{References}

1. Yang H, Testa JR, Carbone M: Mesothelioma epidemiology, carcinogenesis, and pathogenesis. Curr Treat Options Oncol 2008, 9(2-3):147-157.

2. Goodman JE, Nascarella MA, Valberg PA: Ionizing radiation: a risk factor for mesothelioma. Cancer Causes Contro. 2009, 20:1237-1254.

3. Weiner SJ, Neragi-Miandoab S: Pathogenesis of malignant pleural mesothelioma and the role of environmental and genetic factors. $J$ Cancer Res Clin Oncol 2009, 135:15-27.

4. Dogan AU, Baris Y, Dogan M, Emri S, Steele I, Elmishad AG: Genetic predisposition to fiber carcinogenesis causes a mesotheliom epidemic in turkey. Cancer Res 2006, 66:5063-5068.

5. Villani AC, Lemire M, Fortin G, Louis E, Silverberg MS, Collette C, Baba N, Libioulle C, Belaiche J, Bitton A, Gaudet D, Cohen A, Langelier D, Fortin PR, Wither JE, Sarfati M, Rutgeerts P, Rioux JD, Vermeire S, Hudson TJ, Franchimont D: Common variants in the NLRP3 region contribute to Crohn's disease susceptibility. Nat Genet 2009, 41(1):71-76.

6. Pontillo A, Brandao L, Guimaraes R, Segat L, Araujo J, Crovella S: Two SNPs in NLRP3 gene are involved in the predisposition to type- 1 diabetes and celiac disease in a pediatric population from northeast Brazil. Autoimmunity 2010, 43(8):583-589.

7. Qi F, Carbone M, Yang H, Gaudino G: Simian virus 40 transformation, malignant mesothelioma and brain tumors. Expert Rev Respir Med 2011, 5(5):683-697.

8. Robinson C, Van Bruggen I, Segal A, Dunham M, Sherwood A, Koentgen F, Robinson BW, Lake RA: A novel SV40 Tag transgenic model of asbestosinduced mesothelioma: malignant transformation is dose dependent. Cancer Res 2006, 15:10786-10794.

9. Foddis R, De Rienzo A, Broccoli D, Bocchetta M, Stekala E, Rizzo P, Tosolini A, Grobelny JV, Jhanwar SC, Pass HI, Testa JR, Carbone M: SV40 infectious 
induces telomerase activity in human mesothelial cells. Oncogene 2002, 21:1434-1442.

10. Pontillo A, Brandão LA, Guimarães RL, Segat L, Athanasakis E, Crovella S: A $3^{\prime}$ UTR SNP in NLRP3 gene is associated with susceptibility to HIV-1 infection. J Acquir Immune Defic Syndr 2010, 54(3):236-240.

11. Jin Y, Mailloux CM, Gowan K, Riccardi SL, LaBerge G, Bennett DC, Fain PR, Spritz RA: NALP1 in vitiligo-associated multiple autoimmune disease. N Engl J Med 2007, 356(12):1216-1225.

12. Magitta NF, Bøe Wolff AS, Johansson S, Skinningsrud B, Lie BA, Myhr KM, Undlien DE, Joner G, Niølstad PR, Kvien TK, Førre Ø, Knappskog PM, Husebye ES: A coding polymorphism in NALP1 confers risk for autoimmune Addison's disease and type 1 diabetes. Genes Immun 2009, 10(2):120-124

13. Pontillo A, Catamo E, Arosio B, Mari D, Crovella S: NALP1/NLRP1 Genetic variants are associated with Alzheimer disease. Alzheimer Dis Assoc Disord 2011, 26(3):277-281.

14. Kummer JA, Broekhuizen $R$, Everett $H$, Agostini L, Kuijk L, Martinon F, van Bruggen R, Tschopp J: Inflammasome components NALP 1 and 3 show distinct but separate expression profiles in human tissues suggesting a site-specific role in the inflammatory response. J Histochem Cytochem 2007, 55(5):443-452

15. Comar M, Zanotta N, Pesel G, Visconti P, Maestri I, Rinaldi R, Crovella S, Cortale M, De Zotti R: Bovenzi M Asbestos and SV40 in malignant pleural mesothelioma from a hyperendemic area of north-eastern Italy. Tumori 2012, 98(2):210-214.

16. Bruey JM, Bruey-Sedano N, Luciano F, Zhai D, Balpai R, Xu C, Kress CL, BaillyMaitre B, Li X, Osterman A, Matsuzawa S, Terskikh AV, Faustin B, Reed JC: $\mathrm{BCl}-2$ and $\mathrm{BCl}-\mathrm{XL}$ regulate proinflammatory caspase-1 activation by interaction with NALP1. Cell 2007, 129(1):45-56.

17. Wang Y, Faux SP, Hallden G, Kirn DH, Houghton CE, Lemoine NR, Patrick G: Interleukin-1 beta and tumour necrosis factor-alpha promote the transformation of human immortalised mesothelial cells by erionite.ù. Int J Oncol 2004, 25(1):173-178.

18. Krelin Y, Voronov E, Dotan S, Elkabets M, Reich E, Fogel M, Huszar M, Iwakura Y, Segal S, Dinarello CA, Apte RN: Interleukin-1beta-driven inflammation promotes the development and invasiveness of chemical carcinogen-induced tumors. Cancer Res 2007, 67(3):1062-1071.

19. Dostert C, Pétrilli V, Van Bruggen R, Steele C, Mossman BT, Tschopp J: Innate immune activation through Nalp3 inflammasome sensing of asbestos and silica. Science 2008, 320(5876):674-677.

20. Verma D, Lerm M, Blomgran Julinder R, Eriksson P, Söderkvist P, Särndahl E: Gene polymorphisms in the NLRP3 inflammasome Are associated with interleukin-1 production and severe inflammation. Arthritis Rheum 2008, 58(3):888-894

21. Kastbom A, Johansson $M$, Verma $D$, Söderkvist $P$, Rantapää-Dahlqvist $S$ : The CARD8 p.C10X polymorphism associates with the inflammatory activity in early rheumatoid arthritis. Ann Rheum Dis 2009, 69(4):723-726.

22. Ghiringhelli $F$, Apetoh $L$, Tesniere A, Aymeric L, Ma Y, Ortiz C, Vermaelen $K$, Panaretakis T, Mignot G, Ullrich E, Perfettini JL, Schlemmer F, Tasdemir E, Uh M, Génin P, Civas A, Ryffel B, Kanellopoulos J, Tschopp J, André F, Lidereau R, McLaughlin NM, Haynes NM, Smyth MJ, Kroemer G, Zitvogel L: Activation of the NLRP3 inflammasome in dendritic cells induces IL-1betadependent adaptive immunity against tumors. Nat Med 2009, 15(10):1170-1178.

23. Carbone M, Ly BH, Dodson RF, Pagano I, Morris PT, Dogan UA, Gazdar AF, Pass HI, Yang H: Malignant mesothelioma: facts, myths, and hypotheses. J Cell Physiol 2012, 227(1):44-58.

24. Carbone $\mathrm{M}$, Yang $\mathrm{H}$ : Molecular pathways: targeting mechanisms of asbestos and erionite carcinogenesis in mesothelioma. Clin Cancer Res 2012, 18(3):598-604.

25. Okamoto M, Liu W, Luo Y, Tanaka A, Cai X, Norris DA, Dinarello CA, Fujita M: Constitutively active inflammasome in human melanoma cells mediating autoinflammation via caspase-1 processing and secretion of interleukin1beta. J Biol Chem 2010, 285(9):6477-6488.

26. Aymeric L, Apetoh L, Ghiringhelli F, Tesniere A, Martins I, Kroemer G, Smyth MJ, Zitvogel L: Tumor cell death and ATP release prime dendritic cells and efficient anticancer immunity. Cancer Res 2010, 70(3):855-858.

27. Ostrand-Rosenberg S, Sinha P: Myeloid-derived suppressor cells: linking inflammation and cancer. J Immunol 2009, 182(8):4499-4506.

28. Balkwill F, Mantovani A: Inflammation and cancer: back to Virchow? Lancet 2001, 357(9255):539-545.
29. Balkwill F, Coussens LM: Cancer: an inflammatory link. Nature 2004, 431(7007):405-406.

30. Brambilla E, Travis WD, Colby TV, Corrin B, Shimosato Y: The new world health organization classification of lung tumours. Eur Respir J 2001, 18(6):1059-1068.

31. Cox DG, Canzian F: Genotype transposer: automated genotype manipulation for linkage disequilibrium analysis. Bioinformatics 2001, 17:738-739.

32. Barrett JC, Fry B, Maller J, et al: Haploview: analysis and visualization of LD and haplotype maps. Bioinformatics 2005, 21:263-265.

33. Lewis CM: Genetic association studies: design, analysis and interpretation. Brief Bioinform 2002, 3:146-153.

doi:10.1186/1750-9378-7-25

Cite this article as: Girardelli et al:: NLRP1 polymorphisms in patients with asbestos-associated mesothelioma. Infectious Agents and Cancer 2012 7:25.

\section{Submit your next manuscript to BioMed Central and take full advantage of:}

- Convenient online submission

- Thorough peer review

- No space constraints or color figure charges

- Immediate publication on acceptance

- Inclusion in PubMed, CAS, Scopus and Google Scholar

- Research which is freely available for redistribution 